Cuni-Sanchez A, Omeny P, Pfeifer M, Olaka L, Boru M, Marchant R, Burgess

N. Climate change and pastoralists: perceptions and adaptation in montane Kenya. Climate and Development (2018)

DOI link

https://doi.org/10.1080/17565529.2018.1454880

ePrints link

http://eprint.ncl.ac.uk/247194

Date deposited

$04 / 04 / 2018$

Embargo release date

$26 / 03 / 2019$

Copyright

This is an Accepted Manuscript of an article published by Taylor \& Francis in Climate and Development on $26 / 03 / 2018$, available online:

https://doi.org/10.1080/17565529.2018.1454880. 


\title{
Climate change and pastoralists: perceptions and adaptation in montane Kenya
}

\begin{abstract}
Tropical montane forests are amongst the most threatened ecosystems by climate change. However, little is known about climatic changes already observed in these montane areas in Africa, or the adaptation strategies used by pastoralist communities. This article, focused on three mountains in northern Kenya, aims to fill these knowledge gaps. Focus-group discussions with village elders were organised in ten villages on each mountain $(n=30)$. Villages covered different pastoralist ethnic groups. Historical data on rainfall, temperature and fog was gathered from Marsabit Meteorological station.

All participants reported changes in the amount and distribution of rainfall, fog, temperature and wind for the past 20-30 years; regardless of the mountain or ethnicity. They particularly highlighted the reduction in fog. Meteorological evidence on rainfall, temperature and fog agreed with local perceptions; particularly important was a $60 \%$ reduction in hours of fog per year since 1981. Starting farming and shifting to camel herding were the adaptive strategies most commonly mentioned. Some adaptive strategies were only mentioned in one mountain or by one ethnic group (e.g. starting the cultivation of khat). We highlight the potential use of local communities' perceptions to complement climatic records in data-deficient areas, such as many tropical mountains, and emphasise the need for more research focused on the adaptation strategies used by pastoralists.
\end{abstract}

\section{Keywords}

Mountains, pastoralists, perceptions, adaptation, ethnicity

\section{Research highlights}

- Reduced rainfall and fog, and increased temperatures were reported

- An agreement between perceptions and meteorological evidence was observed

- An innovative way to quantify fog changes is presented

- Different ethnic groups used different adaptive strategies

- Start farming and camel herding were commonly used adaptation strategies 


\section{Introduction}

Tropical montane forests (TMFs) are particularly threatened by predicted changes in climate (Bruijnzeel et al., 2011). These forests harbour high levels of biodiversity and endemism, and among other ecosystem services such as regulating climate and provisioning of goods, they provide water to tens of millions of people (Bruijnzeel et al., 2011; Mittermeier et al., 2004). As the rate of warming is amplified with elevation, such mountain environments will experience more rapid changes in temperature than environments at lower elevations (MRI, 2015). Particularly important are warming effects such as a rising cloud base or reduced overall cloud incidence, because clouds (termed fog when you are in it) is an important source of water in many of these ecosystems (Bruijnzeel et al., 2011). Unfortunately, little information is available on the climatic changes actually observed in many of these montane forests (MRI, 2015), especially in Africa.

Recent high-resolution climate projections for Africa indicate that East Africa is likely to experience marked climatic changes, with increased mean annual temperatures and increased rainfall, coupled with increased rainfall seasonality (Platts et al., 2015). However, these projections reveal considerable variation, with spatially complex climates, such as in montane areas, subject to multiple extrema depending on regional climate models (Platts et al., 2015). New research also shows that, contrary to IPCC estimates, the Kenyan highlands have been getting drier and are likely to continue to dry (Eriksen et al., 2011), emphasising the uncertainty regarding previous predictions for the area. In fact, many parts of Africa lack long-term meteorological records, which are important for understanding climatic patterns at the local level.

One strategy which can be used to complement data-scarce areas in terms of meteorological data is local communities' perceptions on climatic changes (Savo et al., 2016). As rural farmers and pastoralists tend to live in the same area where they were born; they are potentially a 'living' record of observed changes in climate (Cuni-Sanchez et al., 2012). A recent review on published studies in 137 countries highlighted the strong agreement between local communities' perceptions and historical meteorological data (Savo et al., 2016). Despite the growing numbers of such studies, to our knowledge, only one study has reported perceived changes in climate in an African mountain, and it only documents perceptions of $<10$ people (Hamilton \& Bensted-Smith, 1989).

Local communities' knowledge can also help suggest more adequate strategies for adapting to climatic change. A significant amount of the literature about climate change perceptions and adaptation and the socio-economic parameters affecting both has been published in the past decade (see Savo et al., 2016 for a review). Most, however, focus on agricultural communities, despite pastoralists being one of the most vulnerable groups to predicted changes in climate (Snorek et al., 2014). For example, in Kenya, more studies have focused on farmers (Bryan et al., 2013; Kalungu et al., 2013; Mugi-Ngenga et al., 2016; Rufino et al., 2013), and farmers having livestock (e.g. Kabubo-Mariara, 2009; Silvestri et al., 2012), rather than on pastoralists (Luseno et al., 2003; Opiyo et al., 2015).

Pastoralists are particularly vulnerable groups to predicted changes in climate for several reasons: 1) they tend to be economically impoverished and heavily dependent on natural resources e.g. for firewood and medicine, 2) they generally occupy less productive lands which are often poorly developed and suffer historical political and economic marginalization; and 3) they are faced with continued severe environmental degradation, 
shrinking resource bases and reduced transhumance mobility routes (Fekadu, 2013; Mwakaje, 2013). Pastoralists have employed several 'traditional' management strategies to cope with, and adapt to climatic changes. For example, they have been using elaborate livestock management strategies based on regular and opportunistic migration in search of sufficient forage and water, herd splitting, rapid destocking, complex gift and loan systems, and raiding of other clans and ethnic groups' herds (Luseno et al., 2003). Newer strategies such as increased crop cultivation (Snorek et al., 2014) and adjustment of herd composition (Rufino et al., 2013) have also been reported. While it has been highlighted that traditional coping mechanisms might no longer be a solution (e.g. mobility has been restricted in Niger, Snorek et al., 2014), other authors suggest that these traditional coping mechanisms are better than other strategies such as sedentarisation (Berhe \& Butera, 2012).

Pastoralist and agro-pastoralist communities also turn to montane forests to cope with climatic changes. In south-eastern Ethiopia, pastoralists collect and trade gum and resins from dry forests during/after drought events, and use this income to buy food and to re-stock small animals after droughts (Worku et al., 2014). In fact, pastoralist communities living near montane forests often rely on these forests for their livelihoods; the forests provide water, firewood, building materials, medicine resources, wild fruits, honey and fodder for their animals, among other cultural and regulating services (Cuni-Sanchez et al., 2016). Income from forests is often the second most important component of the total household income among pastoralists, and it is higher among pastoralists than agro-pastoralists (e.g. Worku et al., 2014).

In Africa, little is known on the specific strategies used by pastoralists living near montane forests to cope with and adapt to climatic changes. This lack of information on adaptive strategies, together with the limited information on observed changes in climate, hampers management decisions both from a conservation and development perspective. This paper, focused on three montane forests in northern Kenya, aims at filling in these knowledge gaps. The main objectives are: 1) to identify the changes in climate as perceived by local pastoralist communities; 2) to assess if these changes agree with meteorological data available and 3) to determine which strategies have been used adapt to these climatic changes. As these montane forests are inhabited by multiple ethnic groups, we also investigated the effects of ethnicity on both climate change perceptions and adaptive strategies used.

\section{Methodology}

\subsection{The study area}

This study focused on the communities living adjacent three forested mountains in northern Kenya: Mt Nyiro (2752m asl), Mt Kulal (2285m asl) and Mt Marsabit (1707m asl) (Figure 1). Most of northern Kenya, which is lowland, is classified as a very arid area with annual rainfall between 150-350 $\mathrm{mm} \mathrm{yr}^{-1}$ (zone VII, Somboerk et al., 1982). However, the mountains we studied are much wetter and cooler, with annual rainfall between $800-1400 \mathrm{~mm} \mathrm{yr}^{-1}$ (semi-humid area, zone III Somboerk et al., 1982). Rainfall is concentrated in two wet seasons, from March to May and from October to December, but great inter-annual variation occurs, with some years having one or no rainy season. Apart from being a dry season grazing ground and an important source of firewood and other non-timber forest products, these forests provide vital hydrological services to the entire region (Cuni-Sanchez et al., 2016). 
Mt Nyiro and Mt Kulal are populated by Samburu pastoralists, while five different ethnic groups live around Mt Marsabit (Figure 1). There are differences between mountains in main livelihood activity, nomadism, access to healthcare, education and markets, some related to Mt Nyiro and Mt Kulal being more isolated geographically and lacking paved roads (Figure 1, Table 1). The ethnic groups studied typically have a subsistence-level production system, with families relying more on milk than meat for nutrition, selling animals to get cash for other economic needs, and building herd sizes to accrue social status, wealth, and provide a buffer against risks such as severe droughts (Bussmann, 2006). In Mt Marsabit, a great percentage of the villages are agro-pastoralists (locals also cultivate maize and beans). In this mountain, the process of encouraging farming among pastoralists so that they become sedentary started during the colonial times, and was in part socio-political (see Little et al., 2001). As most people consider themselves 'pastoralists' because of the cultural implications these has for them, here we will refer to all participants in the study as pastoralists (even those who are agro-pastoralists).

\subsection{Data collection among communities}

Focus-group discussions (FGDs) were organised in ten permanent villages located around each of the three mountains (Figure 1) given a total number of 30 FGDs. All villages in Mt Marsabit and seven villages in Mt Kulal are located within 2-hour walk from the forest. Three villages in Mt Kulal and all in Mt Nyiro are located at lower altitudes, at 6-8h walk from the forest. We sampled most villages within a day walk from these forests. Local communities go into these forests quite often, for different purposes (to collect medicinal plants, firewood), but they go even more often during the dry season, when there are fewer permanent water points outside the forest for livestock/people. In this latter case they might go every 1-2 days.

Each FGD involved 5-10 elders (including the village chief, as it is a custom in the area). All participants were selected on a voluntary basis. The FGDs were facilitated and translated by a person of the same ethnicity as the group being studied and who had previously worked with us in the area. All participants in this study were male (see Supplemental Material for details).

Participants were first informed that the aim of the study was to better understand the perceived changes in climate and its impacts. Then, informal discussions centred on communities' perceptions on differences in climate and the environment, the adaptive strategies they have used to cope with or adapt to these new conditions and their perception of institutional help in the area. All comments made in a single FGD were considered to be a general opinion of the village if no clear disagreement between individuals was observed during the discussion.

Data were pooled per FGD and therefore the FGD was the main unit of analysis. Thematic analysis (Braun \& Clarke, 2006) was used to identify the main themes of the discussions. First, the findings for each theme were grouped by mountain (Mt Nyiro, Mt Kulal and Mt Marsabit, 30 FGDs) to assess differences between locations. Afterwards, those from Mt Marsabit (10 FGDs) were grouped by ethnic group (Samburu, Rendile, Boran, Gabra and Burgi) to assess differences between ethnic groups. The relationships between location/ethnicity and themes were analysed qualitatively, by organising results in tables. 
Cross-tabulation tables were not used due to the high number of cells with expected counts less than 1.

In Mt Marsabit four FGDs were Rendile, four FGDs were Boran, one FGD was Gabra and one FGD was Burgi, as there are no more Gabra and Burgi villages nearby. In six of the 30 villages studied (at least one per mountain), NGOs have started small projects related to adaptation to climate change, such as promotion of camel herding in Loipilipili in Mt Kulal (a village at low altitude). No unique responses or comments were made in FGDs in villages with NGO project compared with those without. This is related to the fact that in our study area, people know what is happening in other villages thanks to word-of-mouth communication and the extended family links. Therefore, even if in a village nobody owns a camel, they have heard from others if this strategy is useful to people or not. We do no further discuss the effects of NGO's projects. Note that we did not investigate differences between richer and poorer households among or within ethnic groups. Previous studies have shown that wealthier households are more likely to adapt to climate change (e.g. Silvestri et al., 2012). However, in remote areas with limited infrastructure and market access (particularly Mt Kulal and Mt Nyiro), wealthier households might have similar options to poorer ones. For instance, Silvestri et al. (2012) showed how greater distance to the urban markets diminishes the probability of using certain adaptive strategies such as destocking and changing feeds.

In this paper the term 'adaptive strategies' refers to two types of strategies: those that have evolved to reduce overall vulnerability to climate shocks (called 'adaptive strategies'), and those evolved to manage their impacts ex-post (named 'coping strategies'), as strategies that might begin as coping strategies in exceptional years can become adaptations for households or whole communities (Morton, 2007). It could be argued that some 'adaptive strategies' mentioned here are related to other non-climatic stresses such as population growth. While this is not the case in Mt Kulal and Mt Nyiro (low population density, isolation), it could be relevant for Mt Marsabit (linked to the pastoralist 'sedentarisation' process). It should be noted that in this study, 'increased farming' as an adaptive strategy refers to two types of farming: rain-fed farming at higher altitudes (villages near the forest) and irrigation farming at lower altitudes. In the latter case, water needs to be transported from higher altitudes (e.g. through pipes). Boreholes are not an option in our study area, as the ground-water table is very deep.

\subsection{Meteorological data}

Monthly rainfall (period 1920-2015), minimum $\mathrm{T}_{\min }$, mean $\mathrm{T}_{\text {mean }}$, and maximum $\mathrm{T}_{\max }$ monthly temperature (period 1974-2013) and daily fog data (period 1980-2015) were obtained from the Kenya Meteorological Department for Marsabit town meteorological station (located on the lee side of the mountain at 1300m asl, Figure 1). While there were no missing values for rainfall and fog, there were no temperature data for 2014 and 2015, due to mechanical failure. The occurrence of fog, defined as visibility $<1000 \mathrm{~m}$, which is the international definition of fog (Tardif \& Rasmussen, 2007) was recorded on an hourly basis (categorical scale: 0-no fog, 1-fog) by the caretaker of the meteorological station. This fog data was used to compute two variables: hours of fog per year and number of days with fog per year (by adding all hours with fog category 1, or days with at least 1 hour of fog category 1 , respectively). Fog occurrence based on visibility has been used in other studies on cloud forest fog seasonality (Alvarado-Barrientos et al., 2014; Garreaud et al., 2008). No smog or pollution could have affected fog estimates as Marsabit town has few vehicles and no industries, despite being the county headquarters. The same caretakers had been in the station 
for over 10 years and reported a clear distinction between the two categories in the scale used. Unfortunately, no other historical meteorological data is available for the other two mountains studied.

Decadal monthly and seasonal averages were computed for rainfall, temperature and fog. Seasonal averages refer to the first rainy season (Mar-May), the second rainy season (Oct$\mathrm{Dec}$ ), the first dry season (Jan-Feb) and the second dry season (Jun-Sep). Annual values were then used to compute the 10-year running mean for rainfall. Number of 'dry years' was computed as number of years in a decade for which annual rainfall below the mean while number of 'cold years' was computed as number of years in a decade for which minimum temperature was below the mean. Because of the shorter historical range of temperature data available, decadal averages were calculated as follows: e.g. 2000s refer to period 2004-2013, while for rainfall 2000s refer to 2000-2009. Temporal trends for rainfall were tested using a linear regression. Trends for days and hours with fog for the period 1981-2015 were modelled using a gamma regression model, as the probability distribution of these two variables was better described by the gamma distribution.

\section{Results and Discussion}

\subsection{Perceptions on climatic changes and explanations}

In all FGDs it was reported that now 1) there were no rains between the rainy seasons and 2) rains were unreliable both in quantity, duration and even in the rainy season event taking place (non-event), see Figure 2. 'Before you would know when the rains would come and how long they would last, now sometimes the rains skip (non-occurrence of rains), and even when it rains you cannot tell if they will be the long rains, the short rains, or useless rains (very little rain)' (participant comment in Mt Kulal). Similarly, communities reported that fog had decreased in amount and duration so that now 1) there was no fog outside the rainy season, and 2) the days with fog have few hours of fog (Figure 2). Some comments made were 'before one could not see the sun for several days or even a whole week', 'before we had to bring our maize to the lowlands so it would dry properly', 'before you could hang your washed clothes and they would not dry for days' (participants' comments in Mt Marsabit). While in Mt Kulal and Mt Marsabit communities reported a general increase in temperatures; in Mt Nyiro they reported no change in temperatures. In all mountains most communities reported increased winds (Figure 2).

Similar changes in rainfall have been reported by communities all over Africa (e.g. CuniSanchez et al., 2012; Egeru, 2016; Megersa et al., 2014). However, only one other published study on local perceptions of climatic changes in Africa reported changes in fog, for the East Usambaras Mountains in Tanzania (Hamilton \& Bensted-Smith, 1989). In this latter study locals reported similar observations to ours, such as 'before the mornings were misty almost all year; now the mist has disappeared expect for the rainy seasons' (Hamilton \& BenstedSmith, 1989). Similar comments are also made by people in the Uluguru Mountains in Tanzania (pers. Obs.) It should be noticed that none of the other abovementioned studies focused on mountain areas where fog might be found. With regard to temperatures, several of studies reported increased temperatures (e.g. Hamilton \& Bensted-Smith, 1989 in Tanzania; Rao et al., 2011 in Kenya). It is possible that changes in temperature are more difficult to perceive (Kalungu et al., 2013), especially because of the large variation between seasons and 
altitude in our study area (the mountains). This might be why communities in Mt Nyiro did not report changes in temperature.

No differences between ethnic groups were observed in perceptions of climatic changes around Mt Marsabit or between mountains (Table 2). In north Benin no differences were also observed between different ethnic groups (Cuni-Sanchez et al., 2012), and it was suggested that the rural poor are so dependent on their environment that they pay special attention to the variation on their local climate, regardless of their ethnic group.

Communities related the perceived changes in climate to God or environmental degradation (destruction of the forest) (about 50\% and 20\% of the FGDs, respectively, see Figure 2). While God was the most common explanation in Mt Nyiro and Mt Kulal, in Mt Marsabit it was environmental degradation. Interestingly, in $20 \%$ of the FGDs, it was mentioned that God was angry at them because of ethnic conflicts and had sent them drought spells (Figure 2). Cattle rustling between ethnic groups has long existed in the area, but droughts increase competition for resources (water points, pasture and cattle), and therefore, fighting. Criminals and businessmen commercialise cattle raids to make quick money from the sale of stolen livestock (Meier et al., 2007). The wrath of cultural spirits and God were also reported as major causes of perceived changes in climate in other African studies (Cuni-Sanchez et al., 2012; Mubaya et al., 2012). Some FGDs also linked the reduction of fog to deforestation, as 'trees attract rains and mist, and with fewer trees, there are fewer rains and mist' (comment made in several FGDs, see Figure 7 Supplemental Material). In the East Usambaras Mountains in Tanzania this link was also made by local communities (Hamilton \& BenstedSmith, 1989). In our study, climate change as being a global phenomenon caused by increased greenhouse gases was not mentioned in any village, even in those where NGOs have started small projects related to climate change adaptation.

Apart from climactic changes, FGDs also highlighted environmental changes. All FGDs mentioned a reduction in the amount and quality of grass available, which was mainly linked to decreased rainfall, but also reduced fog presence and increased numbers of cattle.

Decreased water availability was also mentioned in all FGDs, with streams and wells no longer being available during the whole year, or during some dry years. As several participants in Mt Marsabit reported 'when we were children four streams used to flow the whole year on this side of the mountain, and now for more than a decade, they only exist when it rains'. Changes in forest extension and thickness were also mentioned in some FGDs, especially in Mt Marsabit. In two FGDs in Mt Marsabit it was also declared that crop yields had decreased. A participant in Mt Marsabit commented 'before the fog would keep our seeds alive during the dry months and now there is no fog'. The only change discussed related to cattle was a reduction in milk off-take, mentioned in all 30 FGDs. While in 29 FGDs this was linked to a reduction in the amount and quality of grass, in 13 FGDs (mainly around Mt Marsabit) it was also mentioned that cows have more diseases. Changes in forest extension and thickness, reduced crop yields and a reduction in milk off-take are often reported by pastoralists (e.g. Cuni-Sanchez et al., 2012; Silvestri et al., 2012).

\subsection{Historical meteorological data}

No trend in annual rainfall was observed, but a significant decrease for the 10-year running mean was found (Figure 3). The number of years with annual rainfall below the average has increased for the past three decades (Table 4 Supplemental Material). If decadal monthly and seasonal average rainfall is considered, there has been a decrease for the first rainy season 
and for both dry seasons but not for the second rainy season (Figure 6 Supplemental Material). With regard to fog, historical data indicates a significant reduction in both hours of fog/year and days with fog/ year since 1980 (Figure 4). The reduction in days/ fog a year is independent of the rainy or dry season, with a particularly noticeable decrease in days with fog for the period Jun-Aug (Figure 6 Supplemental Material). No significant trend was observed in annual $\mathrm{T}_{\min }, \mathrm{T}_{\max }$ or $\mathrm{T}_{\text {mean }}$, or increase in annual temperature range or seasonality (Figure not included). However, when decadal monthly and seasonal averages are considered, an increase in $\mathrm{T}_{\min }$ was observed for most months and seasons (Figure 6 Supplemental Material). The number of years with $\mathrm{T}_{\min }$ below the average has also decreased for the past few decades (Table 4 Supplemental Material). Results with regard to $\mathrm{T}_{\max }$ follow the same pattern.

Overall, the historical meteorological data available from Marsabit town confirms the narratives from local people with regard to rainfall, temperature and fog. While several authors have shown the agreement between local perceptions on climatic changes and meteorological data (see Savo et al., 2016 for a review), to our knowledge, this is the first report highlighting the relationship between local perceptions and meteorological data available for fog. This finding indicates that local perceptions can also be used to complement data deficiency areas with regard to fog, not only rainfall and temperature.

In fact, few studies have quantified changes in fog over time (e.g. Beniston et al., 1996 in the Alps) partially because of the lack of quantitative long-term data. Apart from local people's perceptions, we also present a novel approach in which historical meteorological hourly data on visibility is used to assess fog presence and changes over time. Garreaud et al. (2008) used a similar approach to study inter-annual changes in fog persistence between 1985 and 2006 in Fray Jorge NP in Chile, but these authors only had daily data, and there was no significant decrease in fog for the 21-year period they studied. As mentioned by MRI (2015), apart from adding new observations on montane areas, by establishing new climatic stations, we need to locate and evaluate already existing observational data (e.g. visibility data related to fog, local perceptions).

We also highlight that the choice of climatic variables studied is particularly important when comparing perceptions and empirical evidence with regard to climatic changes (Rao et al., 2011). While we did not find significant trends for annual variables, when decadal monthly and seasonal averages are considered, a pattern can be seen. In areas with bimodal rainfall patterns, the seasonal amount and distribution of precipitation is more important than the annual amount in determining primary production that governs livestock population abundance (Megersa et al., 2014).

Our results show that local perceptions of climate variability might provide a valuable addition to MRI (2015)'s suggested use of historical observations, remotely sensed data and model simulations to increase our knowledge on climatic changes on montane areas. This is particularly relevant in regions characterised by high topographic heterogeneity, e.g. small mountains, where modelling and remote sensing data may fail to capture spatial heterogeneity on the ground (Platts et al., 2013; 2015).

\subsection{Adaptive strategies used}

Two adaptive strategies were mentioned in most FGDs in all mountains: increased farming and increased camel herding (Figure 5). Diversifying livelihoods (casual labour or small 
business), migrating longer distances with herds, turning to the forest for fodder and growing fodder grass were mentioned in Mt Nyiro and Mt Marsabit, while reducing the number of animals in the herd and starting the cultivation of khat were mentioned in Mt Kulal and Mt Marsabit (Figure 5). In Mt Marsabit growing drought resistant crop varieties and using wild tubers as fodder were also mentioned (Figure 5). With regard to differences between ethnic groups, some differences were observed in Mt Marsabit (Table 2). For example, while the Boran and Burgi mentioned starting the cultivation of khat and casual labour/small business, Rendile mentioned growing fodder grass, turning to the forest for fodder and using tubers as fodder (Table 2). Burgi were the only group which mentioned growing drought resistant crop varieties (Table 2).

To start farming and to increase the extent of area under farming are strategies reported from pastoralists elsewhere in Africa (Table 3). Farming allows people to store food (maize, beans) which can be consumed during a famine period (drought event during which many livestock dies). Storing maize and beans is easier than storing meat. Shifting to camel herding has been mentioned by Watson (2012) and Opiyo et al. (2015) but not in other recent studies on pastoralists elsewhere in Africa (Table 3) or in Kenya (Rufino et al., 2013). It is well-known that communities whose traditional life has always been based on livestock may hold on to livestock even in the face of severe droughts rather than switch to other species such as camels. The fact that neighbouring ethnic groups have traditionally been camel herders (Rendile, Gabra, see Figure 1) and that Samburu have observed how these animals survive during droughts, might have changed their interests. As a participant reported 'even if we prefer cow milk, at least camels give us milk when there is nothing else'.

Interestingly, to our knowledge, two adaptive strategies had not been reported before in the literature for Africa: the use of wild tubers as fodder and starting the cultivation of khat (Catha edulis). While several studies have reported that herders supplement animals with feed stuffs collected from the fields or the wild including grasses, tree foliage and crop residues (e.g. Megersa et al., 2014), wild tubers had not been reported. The Kenya Agricultural and Livestock Research Organisation (KALRO)-Marsabit office is currently studying these tubers and their nutritional properties. The plant khat (Catha edulis Forsk) is an evergreen shrub native to the Horn of Africa and the Arabian Peninsula, whose chewing giving stimulant effects has been a social custom dating back thousands of years. In the Horn of Africa khat production has spurred an economic boom, but dramatic increases in consumption have raised public health concerns. Moreover, potential implications for food security has also been raised in parts of Ethiopia, Kenya and Yemen as farmers switch from growing food crops to khat (GermanAgroAction, 2009). This is the first report of khat farming as an adaptive strategy to perceived changes in climate. As the khat shrub is evergreen and relatively resistant to droughts (at least more than maize or beans), several innovative pastoralists have started its cultivation: 'khat does not die with drought, and you can always find a buyer for it, so it is better than growing maize or beans' (participant comment in Mt Marsabit).

One adaptive strategy which needs to be further discussed is 'turning to the forest for fodder'. Although this strategy was only mentioned by a few FGDs in Mt Nyiro and Mt Marsabit, results from another study indicate that this is practiced in all villages studied (Cuni-Sanchez et al., 2016). During drought events, when there is no grass left, herders climb trees and cut the branches with machetes to give them to their cows and goats. Possibly, as three months before this study we had organised FGDs to discuss fodder trees (see Cuni-Sanchez et al., 
2018), participants did not reiterate their importance, assuming that this had been previously discussed.

Interestingly, some strategies mentioned by pastoralists in Turkana (a region in northern Kenya near our study area) were not mentioned in this study: selling of livestock before the drought, selling charcoal, firewood or handicrafts and sending children to school (Opiyo et al., 2015). The authors of that study argue that the increasing demand and price for livestock products generated by urban areas provides an incentive for the selling of livestock before the drought. In our study area, there is extremely limited access to urban markets (even Marsabit town has a very small livestock market), which might explain the fact that selling of livestock before the drought, selling charcoal, firewood or handicrafts were not mentioned. Similarly, collection and trade of gum and resins from forests, an adaptive strategy mentioned in southeastern Ethiopia (Worku et al., 2014), were not mentioned in this study, probably, because of the limited access to urban markets.

In this study, the differences observed in adaptive strategies mentioned across ethnic groups could be linked to both access to markets and cultural differences. The Boran and Burgi established near Marsabit town mentioned starting the cultivation of khat and casual labour/small business while the Rendile did not (access to markets differ). Burgi, an ethnic group originally from Ethiopia known to be 'good farmers' by other groups, were the only group which mentioned growing drought resistant crop varieties. Rendile, originally from the lowlands between Mt Marsabit and Mt Nyiro, were the only group which mentioned using tubers as fodder. Most likely, the other ethnic groups do not know the plant species used for this purpose. With regard to villages at higher or lower altitudes, there were no differences between strategies mentioned among these (see results from Mt Kulal, Figure 5).

The main challenges perceived for the two adaptive strategies most mentioned in the FGDs were lack of water for everyone to farm at lower altitudes (where it needs to be piped from the mountain), and the high cost of acquiring a camel (see Table 4 Supplemental Material). Interestingly, villages at lower altitudes highlighted their interest in farming, provided the government or NGOs could help them get piped water, 'we have already cleared and fenced land for it' (participant comment in Sesiai, Mt Nyiro) and villages on top of Mt Kulal highlighted the need for NGOs to also help them acquire camels, "we can keep them in the lowlands with our family members there, we are also very keen to exchange some cows for camels' (participant comment in Lamugul, Mt Kulal). The main challenges perceived in this study, particularly with regard to lack of funds, have been reported elsewhere (e.g., Silvestri et al., 2012; Bryan et al., 2013; Mubaya et al., 2012).

\section{Implications of the results and conclusions}

Interestingly, although Kenya's National Adaptation Programmes of Action (NAPA) pays certain attention to dryland pastoralists, it does not mention northern Kenya montane areas, and therefore, fodder trees as a potential adaptation to droughts, or the possibility to increase rain-fed farming (see NAPA, 2013). Pastoralists' landscapes are not homogenous. If montane forests are available, fodder trees could be sustainably harvested or cultivated, and fog could be trapped with the trees or with nets for irrigation (pers. Obs. in Hurri Hills 2015, also in northern Kenya, see Figure 7 Supplemental Material). Pastoralists themselves are not homogenous either. Even those living in a similar environment (northern Kenya montane forests) might use different adaptive strategies, depending on their ethnic group or location. It 
has been highlighted that interdisciplinary approaches involving rural communities can help assess the most suitable adaptation strategies for a given area as well as their ability and constraints to take up these strategies (Mugi-Ngenga et al., 2016). Although the effectiveness of the local adaptation strategies reported here should be assessed, this study provides new insights on how pastoralist communities living near montane forests in Africa are adapting to the climatic changes perceived, and which adaptive strategies could be attempted elsewhere.

This study has provided novel data on both climatic changes in montane forests in Africa and the effects and adaptation of surrounding pastoralist communities. First, it documents an important reduction in fog for the past 30 years, with important consequences for the environment. Second, it shows changes in rainfall and temperatures, especially on the decadal means. Because of the strong agreement between perceptions and historical meteorological data available, our study supports the notion that local communities' perceptions can be used to complement scientific records. Our research also presents innovative ways to quantify fog changes using long-term visibility data from meteorological stations, opening the possibility of more of such studies in data-deficient montane areas. The paper also shows how pastoralist communities have used a wide range of strategies to adapt to the perceived changes in climate, and how some of these strategies differed between ethnic groups and mountains. More research should focus on pastoralists if we are to help them adapt to the predicted changes in climate.

\section{References}

Alvarado-Barrientos, M.S., Holwerda, F., Asbjornsen, H., Dawson, T.E. \& Bruijnzeel, L.A. (2014). Suppression of transpiration due to cloud immersion in a seasonally dry Mexican weeping pine plantation. Agricultural and Forest Meteorology, 186, 12-25.

Beniston, M. \& Rebetez, M. (1996). Regional behavior of minimum temperatures in Switzerland for the period 1979-1993. Theoretical and Applied Climatology, 53, 231-243.

Berhe, M.G. \& Butera, J.-B. (2012). Climate change and pastoralism: traditional coping mechanisms and conflict in the Horn of Africa. Institute for Peace and Security Studies and University for Peace, Addis Ababa, Ethiopia.

Braun, V., \& Clarke, V. (2006). Using thematic analysis in psychology. Qualitative Research in Psychology, 3, 77-101.

Bruijnzeel, L.A., Mulligan, M. \& Scatena, F.N. (2011). Hydrometeorology of tropical montane cloud forests: emerging patterns. Hydrological Processes, 25, 465-498.

Bryan, E., Ringler, C., Okoba, B., Roncoli, C., Silvestri, S. \& Herrero, M. (2013). Adapting agriculture to climate change in Kenya: Household strategies and determinants. Journal of Environmental Management, 114, 26-35.

Bussmann, R.W. (2006). Ethnobotany of the Samburu of Mt. Nyiru, South Turkana, Kenya. Journal of Ethnobiology and Ethnomedicine, 2:35. 
Cuni-Sanchez, A., Fandohan, B., Assogbadjo, A. \& Sinsin, B. (2012). Local farmers' perception of climate change in Benin (West Africa). Climate and Development, 4, 114-128.

Cuni-Sanchez, A., Pfeifer, M., Marchant, R. \& Burgess, N.D. (2016). Ethnic and locational differences in ecosystem service values: insights from the communities in forest islands in the desert. Ecosystem Services, 19, 42-50.

Cuni-Sanchez, A., Pfeifer, M., Marchant, R., Pompeu P.V. \& Burgess, N.D. (2016). Harvesting fodder trees in montane forests in Kenya: species, techniques used and impacts. New Forests https://doi.org/10.1007/s11056-018-9632-x

Eriksen, P., de Leeuw, J., Thornton, P., Ayantunde, A., Said, M., Herrero, M. \& Notenbaert, A. (2011). Climate Change in Sub-Saharan Africa: consequences and implications for the Future of Pastoralism. International Conference on the Future of Pastoralism, Addis Ababa, 21-23 March 2011.

Egeru, A. (2016). Climate risk management information, sources and responses in a pastoral region in East Africa. Climate Risk Management doi:10.1016/j.crm.2015.12.001.

Fekadu, B. (2013). Multiple tournaments and sustained defection: why do negotiations fail to secure resource access between pastoral and agropastoral groups in Ethiopia? Journal of Socio-Economics, 42, 79-87.

Garreaud, R., Barichivich, J., Christie, D.A. \& Maldonado, A. (2008). Interannual variability of the coastal fog at Fray Jorge relict forests in semiarid Chile. Journal of Geophysical Research, 113:G04011.

GermanAgroAction, (2009). Khat. Addis Ababa: German Agro Action.

Hamilton, A.C. \& Bensted-Smith, R. (1989). Forest conservation in the East Usambara Mountains, Tanzania. IUCN, Gland, Switzerland and Cambridge, UK. 392pp.

Kabubo-Mariara, J. (2009). Global warming and livestock husbandry in Kenya: Impacts and adaptations. Ecological Economics, 68, 1915-1924.

Kalungu, J.W., Filho, W.L. \& Harris, D. (2013). Smallholder farmers' perception of the impacts of climate change and variability on rain-fed agricultural practices in semi-arid and sub-humid regions of Kenya. Journal of Environment and Earth Science, 3, 129-140.

Little, P.D., Smith, K., Cellarius, B.A., Coppock, D.L. \& Barrett, C.B. (2001). Avoiding disaster: diversification and risk management among East African herders. Development and Change, 32, 401-433.

Luseno, W.K., McPeak, J.G., Barrett, C.B., Little, P.D. \& Gebru, G. (2003). Assessing the value of climate forecast information for pastoralists: evidence from southern Ethiopia and northern Kenya. World Development, 31, 1477-1494.

Megersa, B., Markemann, A., Angassa, A., Ogutu, J.O., Piepho, H.-P. \& Zaráte, A.V. (2014). Impacts of climate change and variability on cattle production in southern Ethiopia: perceptions and empirical evidence. Agricultural Systems, 130, 23-34. 
Meier, P., Bond, D. \& Bond, J. (2007). Environmental influences on pastoral conflicts in the Horn of Africa. Political Geography, 26, 716-735.

Mittermeier, R.A., Robles, G.P., Hoffmann, M., Pilgrim, J., Brooks, T., Mittermeier, C.G., Lamoreux, J. \& da Fonseca, G.A.B. (2004). Hotspots Revisited. Garza Garcia N.L. Mexico: CEMEX.

Morton, J.F. (2007). The impact of climate change on smallholder and subsistence agriculture. PNAS, 104, 19680-19685.

Mountain Research Initiative (2015). Elevation-dependent warming in mountain regions of the world. Nature Climate Change, 5, 424-430.

Mubaya, C.P., Njuki, J., Mutsvangwa, E.P., Mugabe, F.T. \& Nanja, D. (2012). Climate variability and change or multiple stressors? Farmer perceptions regarding threats to livelihoods in Zimbabwe and Zambia. Journal of Environmental Management, 102, 9-17.

Mugi-Ngenga, E.W., Mucheru-Muna, M.W., Mugwe, J.N., Ngetich, F.K., Mairura, F.S. \& Mugendi, D.N. (2016). Household's socio-economic factors influencing the level of adaptation to climate variability in the dry zones of Eastern Kenya. Journal of Rural Studies, 43, 49-60.

Mwakaje, A.G. (2013). The impact of climate change and variability on agro-pastoralists' economy in Tanzania. Environmental Economics, 4, 30-38.

National Adaptation Plan of Action for Climate Change (2013). Government of Kenya, available at http://unfccc.int/

Opiyo, F., Wasonga, O., Nyangito, M., Schilling, J., \& Munang, R. (2015). Drought adaptation and coping strategies among the Turkana pastoralists of northern Kenya. International Journal of Disaster Risk Science, 6, 295-309.

Platts, P.J., Gereau, R.E., Burgess, N.D. \& Marchant, R. (2013). Spatial heterogeneity of climate change in an Afromontane centre of endemism. Ecography, 36, 518-530.

Platts, P.J., Omeny, P.A. \& Marchant, R. (2015). AFRICLIM: high-resolution climate projections for ecological applications in Africa. African Journal of Ecology, 53, 103-108.

Rao, K.P.C.., Ndegwa, W.G., Kizito, K. \& Oyoo, A. (2011). Climate variability and change: farmer perceptions and understanding of intra-seasonal variability in rainfall associated risk in semi-arid Kenya. Experimental Agriculture, 47, 267-291.

Rufino, M.C., Thornton, P.K., Ng'ang'a, S.K., Mutiea, I., Jones, P.G., van Wijk, M.T. \& Herrero, M. (2013). Transitions in agro-pastoralist systems of East Africa: Impacts on food security and poverty. Agriculture, Ecosystems and Environment, 179, 215-230.

Savo, V., Lepofsky, D., Benner, J.P., Kohfeld, K.E., Bailey, J. \& Lertzman, K. (2016). Observations of climate change among subsistence-oriented communities around the world. Nature Climate Change, 6, 462-473. 
Silvestri, S., Bryan, E, Ringler, C., Herrero, M., \& Okoba, B. (2012). Climate change perception and adaptation of agro-pastoral communities in Kenya. Regional Environmental Change, 12, 791-802.

Snorek, J., Renaud, F.G. \& Kloos, J. (2014). Divergent adaptation to climate variability: a case study of pastoral and agricultural societies in Niger. Global Environmental Change, 29, 371-386.

Sombroek, W.G., Braun, H.M.H. \& van der Pouw, B.J.A. (1982). Exploratory Soil Map and AgroClimatic Zone Map of Kenya, 1980. Scale: 1:1'000'000. Exploratory Soil Survey Report No. E1. Kenya Soil Survey Ministry of Agriculture - National Agricultural Laboratories, Nairobi, Kenya.

Tardif, R. \& Rasmussen, R.M. (2007). Event-based climatology and typology of fog in the New York City region. Journal of Applied Meteorology and Climatology, 46, 1141-1168.

Watson, E.E. (2012). Religion and Climate Change in Northern Kenya: New Moral Frameworks for New Environmental Challenges? Journal for the Study of Religion, Nature and Society, 6, 319-343.

Worku, A., Pretzsch, J., Kassa, H. \& Auch, E. (2014). The significance of dry forest income for livelihood resilience: the case of the pastoralists and agro-pastoralists in the drylands of south-eastern Ethiopia. Forest Policy and Economics, 41, 51-59. 


\section{Tables and figures}

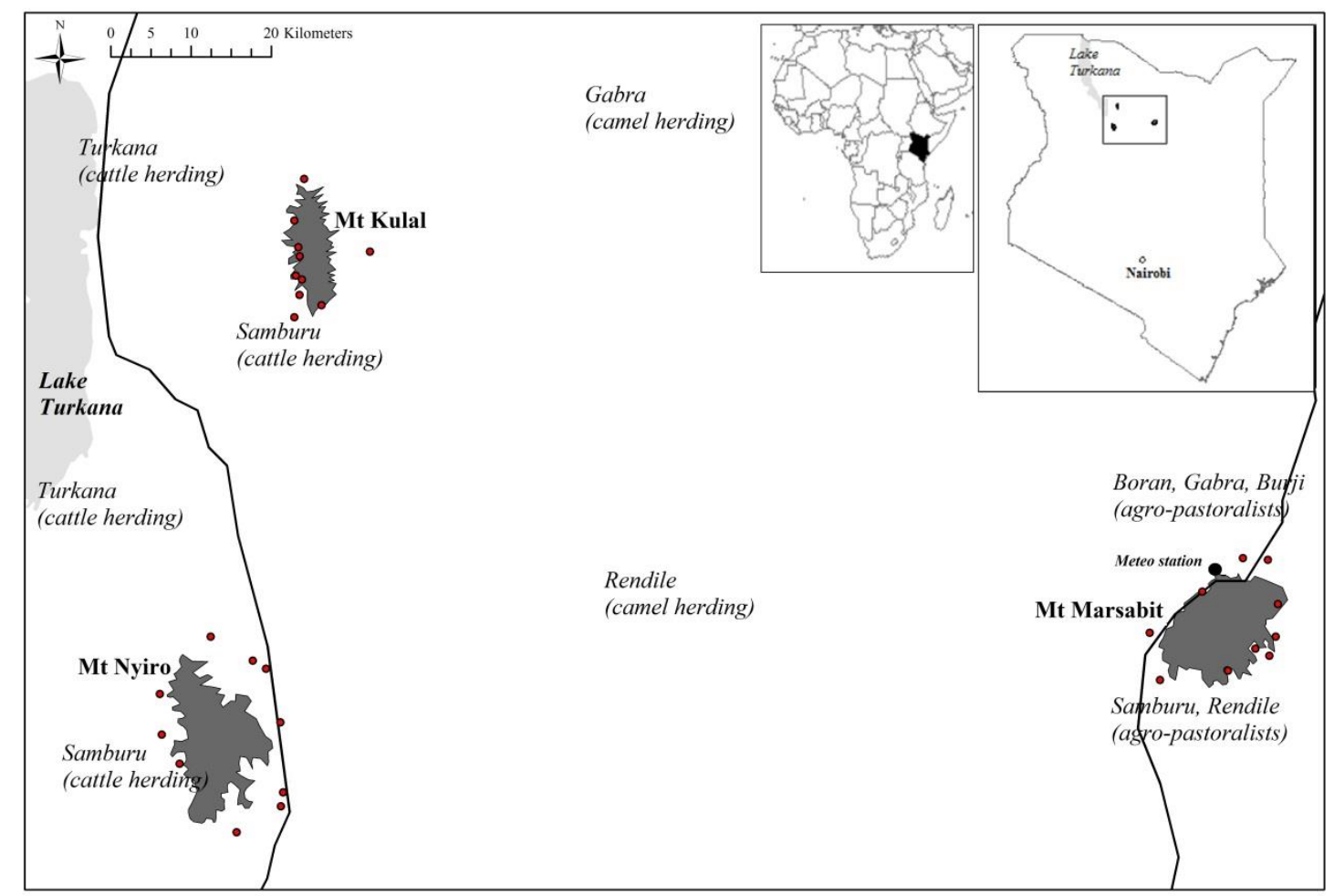

Figure 1. Selected mountains in northern Kenya, villages where focus-group discussions were organised and Marsabit Meteorological station, with regard to main ethnic groups in the area. Black lines refer to major roads, the one passing Mt Marsabit is tarmac while the one near Mt Nyiro is non-paved. Dark grey areas to montane forests and red dots to villages studied. Mt Nyiro (2752m), Mt Kulal (2285m) and Mt Marsabit (1707m). 
Perceptions on climatic changes 20 40 60 80 100

$\begin{array}{llllll}0 & 20 & 40 & 60 & 80 & 100\end{array}$

Now there are no rains between rainy seasons Now rainy seasons are unreliable (quantity/duration)

Now no fog outside rainy season Now the days with fog have few hours of fog In general now it is hotter Temperature has not changed In general now it is more windy

Possible explanations Destruction of the forest

God knows

God is annoyed because people fight

We do not know why
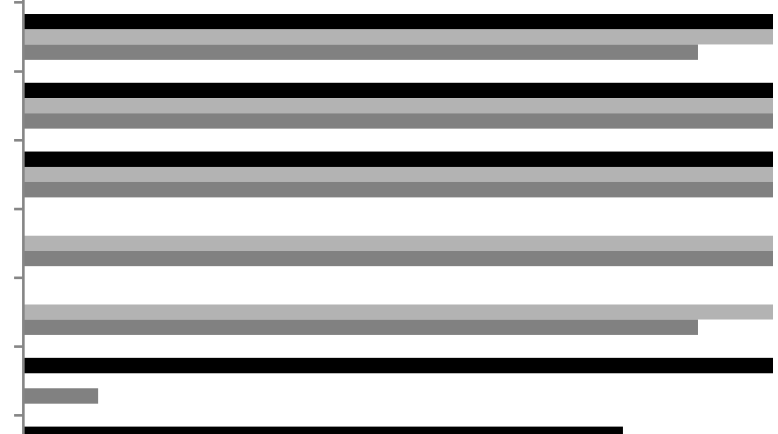

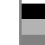
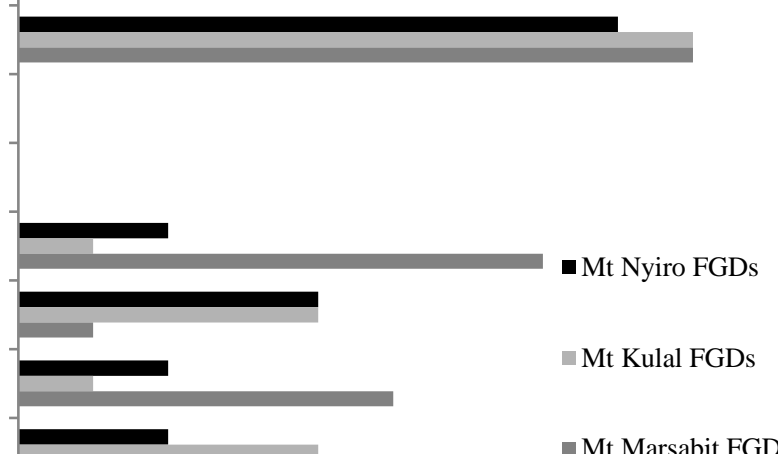

Mt Kulal FGDs

Mt Marsabit FGDs

Figure 2. Perceived changes in rainfall, fog, temperature and wind and potential explanations for these changes with regard to percentage of focus-group discussions in each mountain. FGD refer to focus group discussion $(\mathrm{n}=10$ in each mountain) 


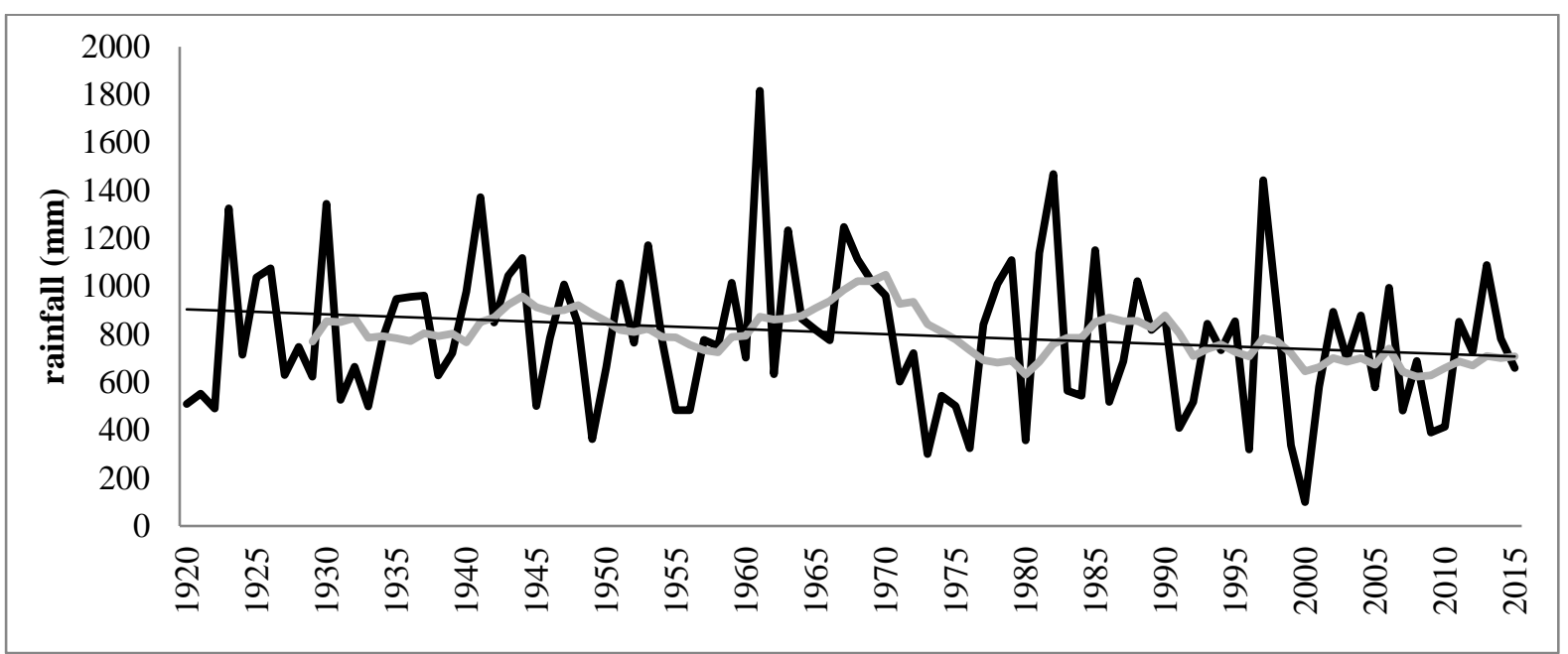

Figure 3. Annual rainfall for Marsabit Meteorological station, $1300 \mathrm{~m}$, lee side mountain. Black line refers to annual rainfall and running mean (grey line) refers to the 10-year running average. Trend for annual rainfall is not significant (line not included) but trend for running mean (thin black line) is significant at $\mathrm{p}<0.05\left(\mathrm{R}^{2}=0.3\right)$. 

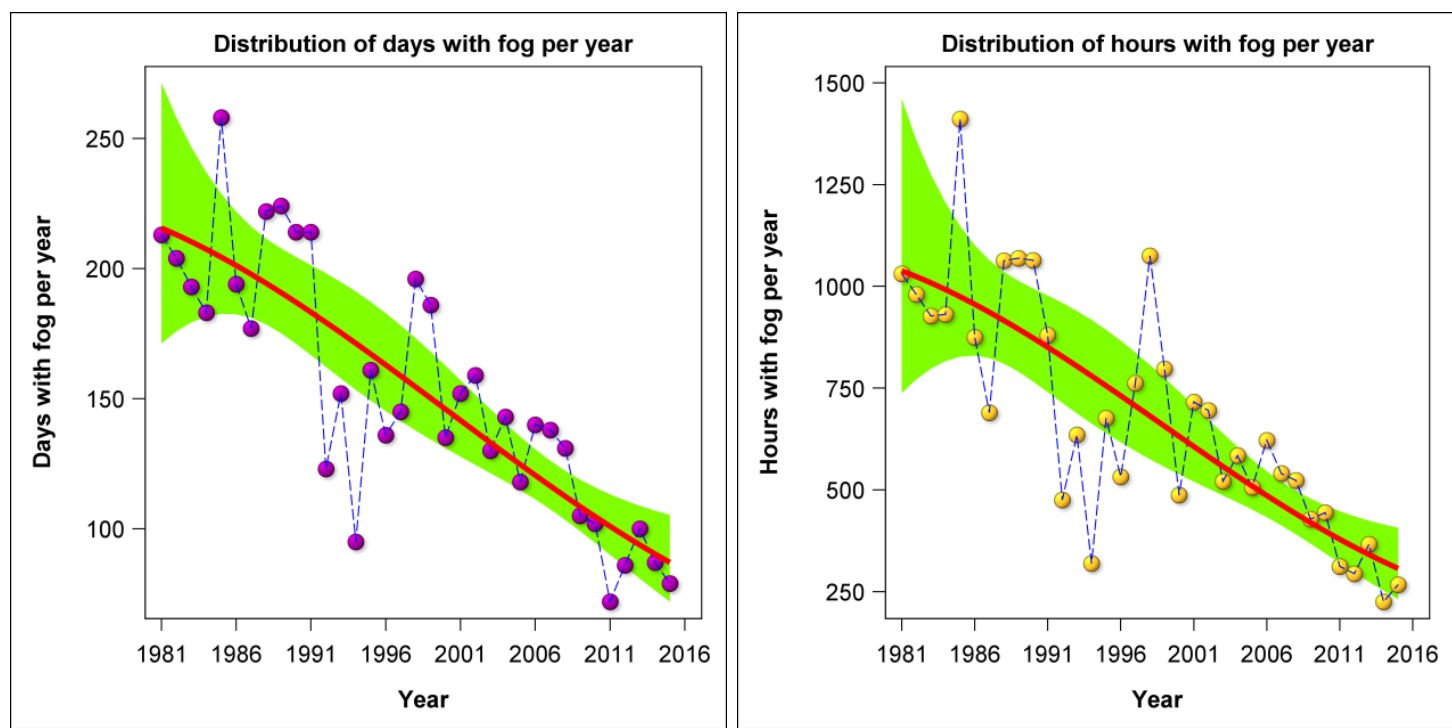

Figure 4. Trend from 1981 to 2016 in days with fog per year (left) and trend of hours with fog per year (right) modelled using a gamma regression model. The red line shows the modelled linear trend with the $95 \%$ confidence band for each shown in green.

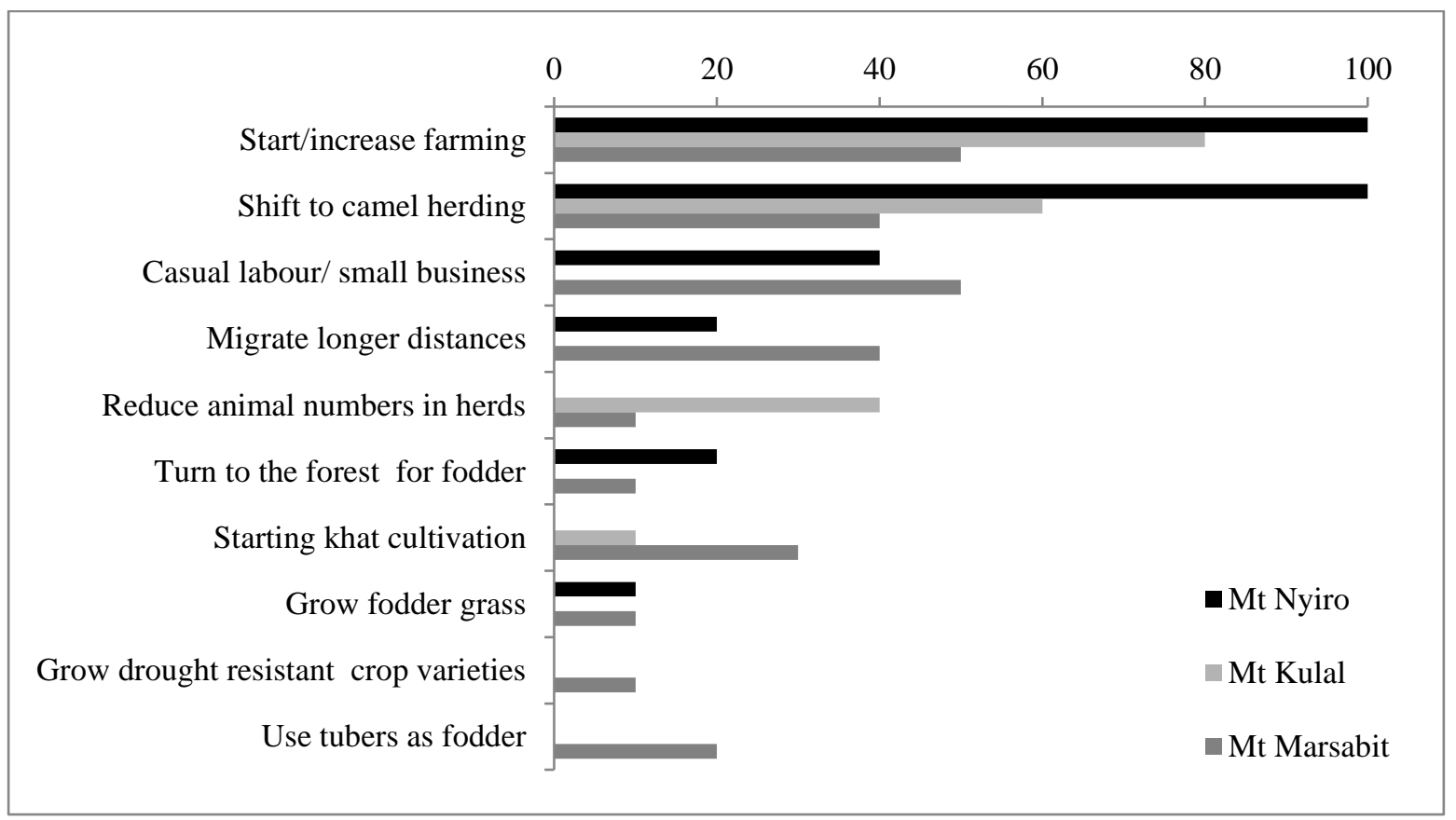

Figure 5. Adaptive strategies mentioned by the different communities with regard to percentage of focus groups discussions per mountain (note $\mathrm{n}=10$ in each mountain). 
Table 1. Overview of the main livelihood activity, nomadism, access to healthcare, education and markets on the mountains studied.

\begin{tabular}{lllll} 
& main livelihood & nomadism & $\begin{array}{l}\text { access to healthcare } \\
\text { and education }\end{array}$ & access to markets \\
\hline Mt Nyiro & pastoralism & common & extremely limited & extremely limited \\
Mt Kulal & pastoralism & common & extremely limited & extremely limited \\
Mt Marsabit & agro-pastoralism* & few families & middle & middle \\
\hline
\end{tabular}

*Agro-pastoralists cultivate maize (Zea mays) and beans (Phaseolus vulgaris) and mainly have cows and goats.

Table 2. Perception on climatic changes observed and adaptive strategies used with regard to the different ethnic groups sampled in Mt Marsabit. $\mathrm{N}$ refers to the number of focus-group discussions carried out with that ethnic group.

\begin{tabular}{|c|c|c|c|c|}
\hline & $\begin{array}{c}\text { Rendile } \\
(\mathrm{n}=4)\end{array}$ & $\begin{array}{c}\text { Borana } \\
(n=4)\end{array}$ & $\begin{array}{c}\text { Gabra } \\
(\mathbf{n}=\mathbf{1})\end{array}$ & $\begin{array}{l}\text { Burgi } \\
(n=1)\end{array}$ \\
\hline \multicolumn{5}{|l|}{ Perceptions on climatic changes } \\
\hline $\begin{array}{l}\text { Now there are no rains between rainy seasons } \\
\text { Now rainy seasons are unreliable }\end{array}$ & 3 & 4 & 1 & 1 \\
\hline (quantity/duration) & 4 & 4 & 1 & 1 \\
\hline Now no fog outside rainy season & 4 & 4 & 1 & 1 \\
\hline Now the days with fog have few hours of fog & 4 & 4 & 1 & 1 \\
\hline In general now it is hotter & 3 & 4 & 1 & 1 \\
\hline Temperature has not changed & 1 & & & \\
\hline In general now it is more windy & 4 & 3 & 1 & 1 \\
\hline
\end{tabular}

\section{Adaptive strategies used}

Reduce number of animals in herds

Start/increase farming

$\begin{array}{llll} & 1 & & \\ 2 & 1 & 1 & 1 \\ & 2 & & 1 \\ & 4 & & \\ 1 & 2 & 1 & \\ 3 & & 1 & \\ 1 & & & \\ 1 & & & \\ 2 & & & \end{array}$

Starting the cultivation of kath

Casual labour/ small business

Shift to camel herding

Migrate longer distances

Grow fodder grass

Turn to the forest for fodder

Use tubers as fodder 
1 Table 3 Comparison between adaptive strategies mentioned in this study and other recent studies published on pastoralists or agro-pastoralists in Africa.

\begin{tabular}{|c|c|c|c|c|c|c|c|c|}
\hline & $\begin{array}{l}\text { This } \\
\text { study* }\end{array}$ & Turkana $^{1}$ & Garissa $^{2}$ & $\begin{array}{l}\text { southern } \\
\text { Ethiopia }^{3}\end{array}$ & Tanzania $^{4}$ & Uganda $^{5}$ & Niger $^{6}$ & Benin $^{7}$ \\
\hline Migrate longer distances & $\mathrm{x}$ & $\mathrm{x}$ & $\mathrm{x}$ & $\mathrm{x}$ & $\mathrm{x}$ & $\mathrm{x}$ & $\mathrm{x}$ & $\mathrm{x}$ \\
\hline Reduce the number of animals in herds & $\mathrm{x}$ & $\mathrm{x}$ & $\mathrm{x}$ & & $\mathrm{x}$ & & $\mathrm{x}$ & $\mathrm{x}$ \\
\hline Shift to camel herding & $\mathrm{x}$ & $\mathrm{x}$ & & & & & & \\
\hline Grow fodder grass & $\mathrm{x}$ & & & $\mathrm{x}$ & & & $\mathrm{x}$ & \\
\hline Use tubers as fodder & $\mathrm{x}$ & & & & & & & \\
\hline Start/increase farming & $\mathrm{x}$ & & & & & $\mathrm{x}$ & $\mathrm{x}$ & $\mathrm{x}$ \\
\hline Starting the cultivation of kath & $\mathrm{x}$ & & & & & & & \\
\hline Grow drought resistant crop varieties & $\mathrm{x}$ & & & & & & & \\
\hline Turn to the forest for fodder & $\mathrm{x}$ & & & & & & & \\
\hline Casual labour/ small business & $\mathrm{x}$ & $\mathrm{x}$ & $\mathrm{x}$ & & & & $\mathrm{x}$ & \\
\hline Sell cattle & & $\mathrm{x}$ & $\mathrm{x}$ & $\mathrm{x}$ & & $\mathrm{x}$ & $\mathrm{x}$ & \\
\hline Change from cattle to goats and sheep & & $\mathrm{x}$ & & & $\mathrm{x}$ & & & \\
\hline Rural-urban migration & & $\mathrm{x}$ & & & $\mathrm{x}$ & & $\mathrm{x}$ & \\
\hline Firewood or charcoal commercialisation & & $\mathrm{x}$ & & & & $\mathrm{x}$ & & \\
\hline Honey production & & $x$ & & & & & & \\
\hline Selling Aloe vera, baskets, handicrafts & & $\mathrm{x}$ & & & & & & \\
\hline Training in livestock health provision & & $x$ & & & & & & \\
\hline Sending children to school & & $\mathrm{x}$ & & & & & & \\
\hline
\end{tabular}

Sending children to school

*This study refers to all 30 focus-group discussions in the three mountain studied. ${ }^{1}$ Opiyo et al., $2015,{ }^{2}$ Silvestri et al., $2012,{ }^{3}$ Megersa et al., $2014 ;{ }^{4}$ Mwakaje, $2013 ;{ }^{5}$ Egeru,

2016 ; ${ }^{6}$ Snorek et al., 2014, ; ${ }^{7}$ Cuni-Sanchez et al., 2012. Note that 1-2 are other region in northern Kenya, located east and west of our study area respectively, in the
lowlands.
The
studies
1-7
were
not
carried
out
near
a
montane
forests. 
